\title{
Gamificação no Ensino da Histologia Humana
}

\author{
Wesley F. M. Brandão ${ }^{1}$, Thaíse C. S. Lima1, Giciane C. Vieira ${ }^{2}$, Bruno T. Mendes² \\ ${ }^{1}$ Universidade Federal da Paraíba (UFPB) \\ Campus I - Cidade Universitária - 58059-900 - João Pessoa - PB - Brasil. \\ ${ }^{2}$ Departamento de Morfologia \\ Universidade Federal da Paraíba (UFPB) - João Pessoa, PB - Brasil \\ owesleybrandao@gmail.com, thaise.carolines@gmail.com,
gicianecvieira@ccs.ufpb.br, bruno.tenorio@ccs.ufpb.br
}

\begin{abstract}
This article describes the experience of incorporating gamification into the teaching practice of Human Histology. Digital technological resources such as Kahoot, Plicker and PowerPoint were used, as well as non-digital technological resources developed by the researchers such as the Histological Puzzle and the Microscope Hunt. It was observed that elements present in games can be used to make the teaching-learning process more interactive, motivating and pleasant, besides increasing the student interest and, consequently, their performance.
\end{abstract}

Resumo. Este artigo descreve a experiência da incorporação da gamificação na prática de ensino da Histologia Humana. Foram utilizados recursos tecnológicos digitais, como Kahoot, Plicker e PowerPoint, bem como recursos tecnológicos não digitais desenvolvidos pelos pesquisadores como o Quebra-cabeça Histológico e o Caça ao Microscópio. Observou-se que elementos presentes nos jogos podem ser utilizados para tornar o processo ensino-aprendizagem mais interativo, motivador e prazeroso, além de aumentar o interesse do aluno e consequentemente, o seu desempenho escolar.

\section{Introdução}

A Histologia é uma das disciplinas básicas dos cursos da área da saúde, sendo um componente essencial para a formação dos profissionais, uma vez que, através dela, eles podem relacionar as estruturas histológicas e microscópicas do organismo com as atividades práticas inerentes à sua profissão. Sendo assim, esta disciplina torna-se de suma importância para a formação profissional do aluno, contribuindo também para o seu desenvolvimento como pesquisador [Burity e Cardozo 2014].

A estratégia de ensino tradicional da Histologia é baseada em aulas teóricas, onde o professor transmite as informações sobre os tecidos e sistemas do corpo, enquanto os alunos recebem a informação. Além disso, as aulas teórico-práticas são complementares às teóricas, nas quais são exploradas lâminas histológicas com o objetivo de identificar estruturas microscópicas dos tecidos humanos presentes no corpo. Neste cenário, considera-se que o 
professor assume um papel "ativo", ao transmitir conhecimento, enquanto que os alunos atuam de forma "passiva" [Alonso 2018].

Por isso, diante da dinamicidade existente no processo de ensino-aprendizagem, surge também a necessidade de estimular a participação e a interação entre os indivíduos presentes na sala de aula para a construção colaborativa de saberes, criando, desta maneira, um ambiente onde os discentes envolvem-se ativamente na aquisição de conhecimentos [Ribeiro 2018].

Atualmente, observa-se uma mudança progressiva na prática dos professores à medida que eles passam a atuar como facilitadores e mediadores entre o aluno e o conhecimento, estimulando-os a desenvolver comportamentos ativos, reflexivos e críticos [Cavadas et al. 2017]. As metodologias ativas acreditam que a elaboração de atividades na sala de aula deve trazer os alunos a participar ativamente do processo de ensinoaprendizagem. Diante disso, pode-se identificar três aspectos comuns nas metodologias que melhoram a aprendizagem, são eles: a cooperação e colaboração entre estudantes e professores; os estudantes devem produzir conhecimento e tomar decisões que envolvem ações [Fildago-Blanco; Sein-Echaluce; García-Penalvo 2019].

As possibilidades de metodologias ativas que permitem o aprofundamento dos assuntos abordados em aula de maneira interativa são diversas e algumas já consolidadas, como aprendizagem baseada em problemas, estudos de caso, aprendizagem baseada em desafios, além da sala de aula invertida e a aprendizagem promovida através da gamificação [Cavanagh et al. 2018].

Nos últimos anos, a sociedade encontra-se cada vez mais imersa nos meios digitais. Nesse sentido, e mediante o avanço tecnológico, a implementação de recursos digitais como ferramentas pedagógicas na sala de aula é crescente. Os recursos digitais trouxeram novas possibilidades de organização de atividades em sala de aula, capazes de motivar os alunos a participarem mais ativamente [Ribeiro e Gil 2016]. A implementação de games, a exemplo do Kahoot, tendem a fazer com que os alunos passem a se empenhar mais na busca pela vitória durante os desafios [Maranhão; Reis 2019], podendo de modo intuitivo colaborar no processo de ensino-aprendizagem dos mesmos de maneira ativa [De Ovando Solís; Rodriguez; Hullin 2018] .

Desse modo, a gamificação está se tornando cada vez mais evidente, uma vez que através delas, o aluno passa da posição passiva, no processo de aprendizagem, para a posição ativa, se tornando o centro do seu próprio aprendizado e garantindo uma maior independência em relação ao professor [Maranhão e Reis 2019]. Portanto, podem ser descritos alguns elementos constituintes das metodologias ativas de ensino, como: autonomia do aluno, inovação, reflexão e trabalho em equipe. Justificando, portanto, a importância da inserção de ferramentas metodológicas ativas em sua prática profissional, visto que, elas possuem o potencial de tornar mais eficiente o processo de ensino-aprendizagem [Diesel; Baldez; Martins 2017].

Diante disso, o trabalho tem por objetivo descrever a experiência do processo criativo e de implementação de atividades desenvolvidas pelos monitores do projeto de monitoria em Histologia Humana da Universidade Federal da Paraíba (UFPB), o qual visava auxiliar no processo ensino-aprendizagem dos discentes que cursaram a referida disciplina. 


\section{Metodologia de trabalho}

\subsection{Seleção e construção dos recursos tecnológicos}

A inserção dos recursos de gamificação foram implementados entre 2019 e 2020, sendo estes agrupados nas categorias de recursos digitais e não digitais baseado na necessidade ou não de algum aparelho digital durante sua execução.

\subsubsection{Recursos tecnológicos digitais}

O Kahoot! é um recurso de gamificação que consiste na aplicação de questionários no formato de "quizzes" proporcionando uma aprendizagem ativa a partir de elementos como autonomia do aluno, inovação, reflexão e trabalho em equipe a fim de despertar o interesse, motivação e engajamento, desenvolvendo habilidades e aumentando o rendimento do aluno [Silva e Sales 2019].

Os alunos foram incentivados a fazer o download do aplicativo em seus celulares e inserir o PIN gerado pela plataforma para iniciar o jogo. Foram acordadas com os alunos as seguintes regulamentos: a) não é permitido consulta de nenhum tipo; b) tempo para cada tipo de questão, sendo disponibilizados 60 segundos para resolução de questões de múltipla escolha e 30 segundos para as do tipo "verdadeiro ou falso"; c) inserção do código de acesso (PIN). As questões abordadas no Kahoot! eram do tipo teóricas e práticas, com fotomicrografias de tecidos e sistemas do corpo humano, conforme ilustrado na figura 1.
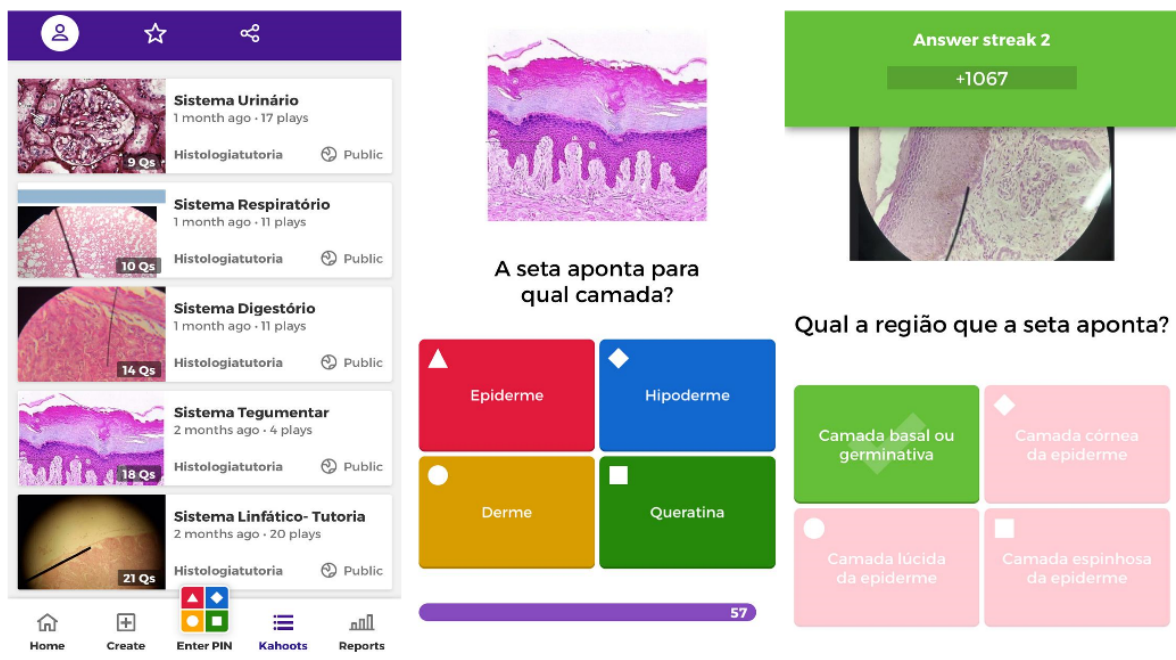

Figura 1. Utilização do Kahoot! na aula de Histologia Humana

Outro aplicativo utilizado foi o Plicker, que permite reunir informações dos alunos a partir de suas respostas a perguntas de múltipla. A coleta das resposta é realizada em tempo real através do reconhecimento de $Q R$ Code por um dispositivo mobile [Attard e Holmes 2020]. Com o auxílio de um projetor, perguntas teóricas e práticas eram projetadas na sala de aula. Foi estipulado o tempo de um minuto e meio para que os os alunos pensassem em suas respostas e levantassem seus $Q R$ Code para serem escaneados. As respostas dos alunos eram computadas na base de dados da plataforma online do Plicker, onde o monitor identificava os alunos que acertaram e erraram. A partir da análise dessas respostas, uma nova explanação do assunto era dada. 


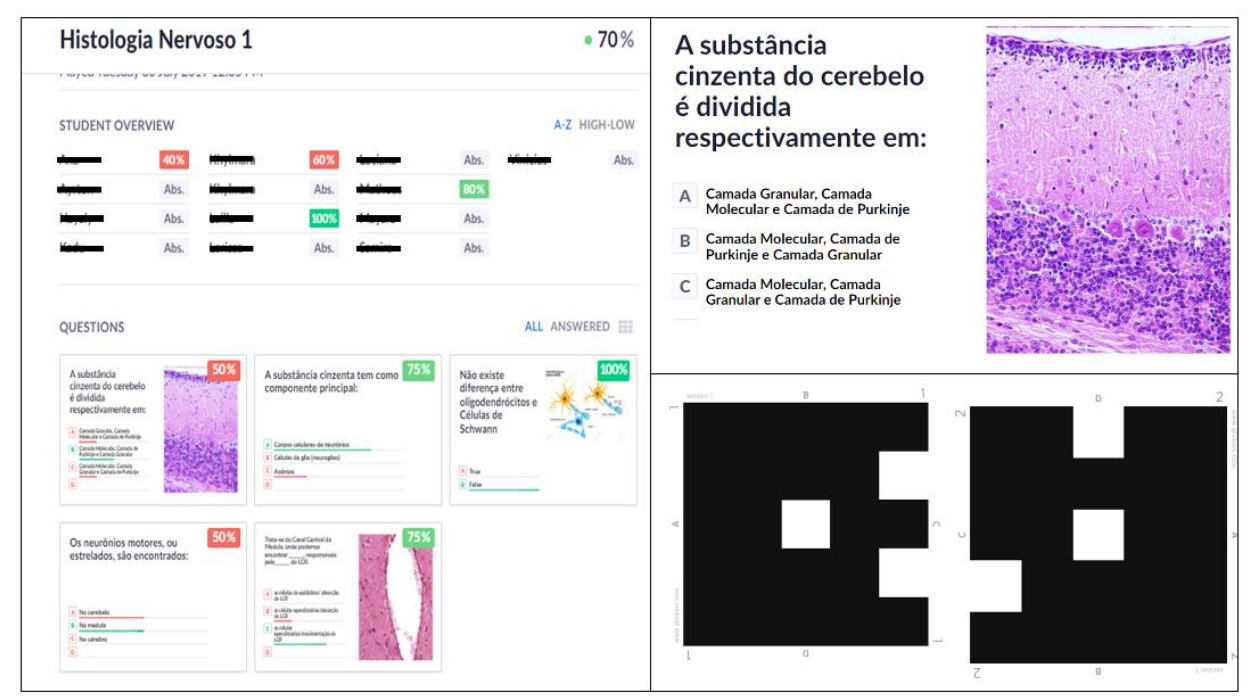

Figura 2. Utilização do Plicker na aula de Histologia Humana

Por fim, com o auxílio do PowerPoint foi desenvolvido o Histoshow - o show dos tecidos. Trata-se de uma gincana com propósito de revisar os conteúdos antes da aplicação da avaliação da unidade. O Histoshow foi inspirado pelo programa de televisão norteamericano Jeopardy! e adaptado para o formato de gincana. As categorias do dia foram apresentadas aos alunos juntamente com sua pontuação, a qual variava entre 100 e 500 pontos de forma que as perguntas mais complexas apresentavam maior pontuação.

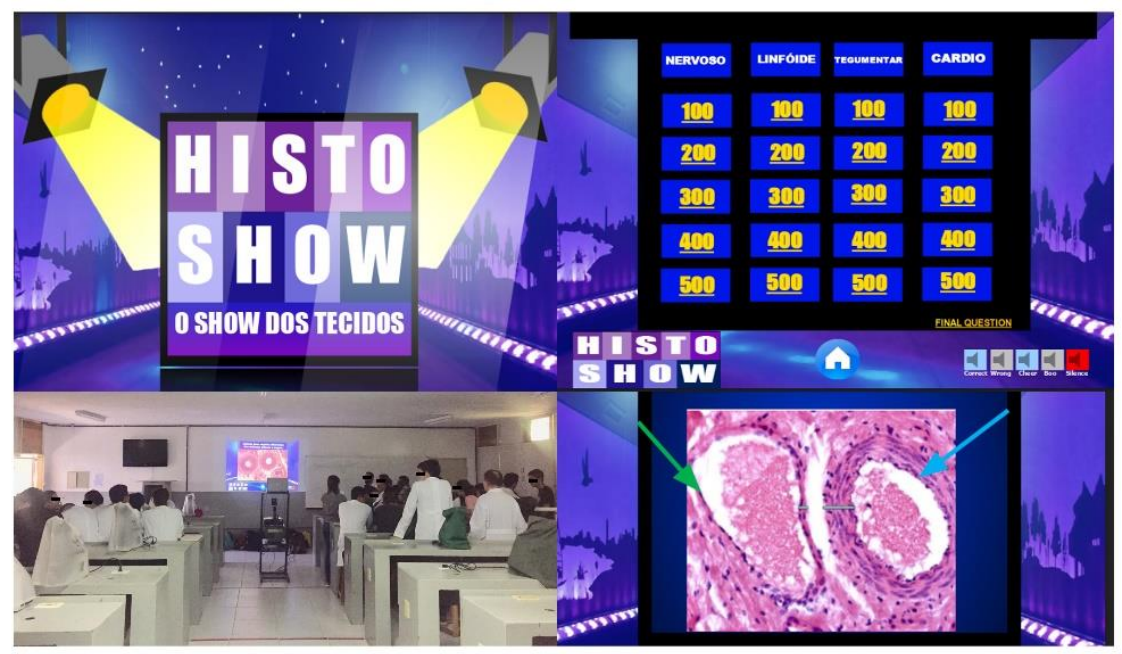

Figura 3. Game de revisão: Histoshow - o show dos tecidos

\subsubsection{Recursos tecnológicos não digitais}

O "Quebra-cabeça Histológico" foi um jogo didático idealizado com o objetivo de estimular os alunos a estabelecerem uma relação entre a imagem microscópica do órgão estudado com as suas características morfológicas. As peças do quebra-cabeça eram formadas por recortes de uma lâmina histológica impressas em uma folha A4 de papel $230 \mathrm{~g}$ que foram dispostas na bancada da sala de aula. Em seguida, os monitores descreveram oralmente as características morfológicas de cada porção dos órgãos estudados, enquanto que os alunos, em conjunto, 
eram estimulados a identificarem e classificarem as porções através do que ouviam e visualizavam nas peças dispostas na bancada. O órgão estudado tomava forma a medida que o quebra-cabeça era construído. Algo semelhante já foi utilizado no ensino da morfologia antes [Risnes et al. 2018], demonstrando ser eficiente para a apreciação das variações da morfologia dentária.

Ademais, também foi utilizado um recurso denominado "Caça ao microscópio", o qual é um jogo projetado com o intuito de incitar o aluno a identificar e classificar as lâminas histológicas referentes à aula. Assim, essa dinâmica estimula o estudante a movimentar-se pelo ambiente. Nesse jogo, os alunos foram divididos em duplas, as quais receberam um "cartão-resposta" com a identificação histológica de uma lâmina de um determinado microscópio. Desse modo, os pares de alunos tiveram $10 \mathrm{~min}$ para visualizar todos os microscópios e "caçar" aquele correspondente ao seu cartão-resposta. Com o término do tempo estipulado, o monitor revisou todas as bancadas, sanando as dúvidas e respondendo se o microscópio encontrado pelo aluno é relativo ao cartão entregue.

\subsection{Planejamento dos encontros semanais}

Durante os encontros com os alunos foram abordados oito sistemas, sendo eles: endócrino, nervoso, cardiovascular, linfóide, tegumentar, digestório e suas glândulas anexas, urinário e respiratório. Além de revisões dos conteúdos já estudados para cada avaliação. Um recurso foi incorporado na abordagem de cada assunto, conforme apontado na tabela 1.

Tabela 1. Relação dos assuntos abordados e os recursos utilizados nos encontros com os alunos

\begin{tabular}{cc}
\hline Assunto abordado & Recurso utilizado \\
\hline Sistema Endócrino & Caça ao Microscópio \\
Sistema Nervoso & Plicker \\
Sistema Cardiovascular & Kahoot \\
Órgãos Linfóides & Quebra-cabeça histológico \\
Sistema Tegumentar & Plicker \\
Revisão para Primeira Avaliação & Histoshow \\
Sistema Digestório & Quebra-cabeça Histológico \\
Glândulas Anexas ao Sistema Digestório & Kahoot \\
Sistema Urinário & Caça ao Microscópio \\
Sistema Respiratório & Kahoot \\
Revisão para Segunda Avaliação & Histoshow \\
\hline
\end{tabular}

\section{Resultados e Discussão}

Sabe-se que as metodologias ativas estão sendo muito utilizadas e que elas têm apresentado bons resultados, uma vez que fazem uso de estratégias e recursos que visam amenizar os 
problemas relacionados ao ensino e aprendizagem [Moraes e Castellar 2018]. Dessa forma, por meio da implementação de jogos na sala de aula, observou-se que houve a promoção de um ambiente de interação entre monitores e alunos, assim como os alunos entre si. $\mathrm{O}$ engajamento dos alunos aumentava à medida que o jogo avançava, especialmente quando os pontos eram acumulados, como no aplicativo Kahoot! e durante o Histoshow. Consequentemente, a criação de um ambiente que gerou competitividade, ocasionou o maior interesse dos alunos no que se refere à aprendizagem, fornecendo maiores resultados e rendimento dos estudantes.

Os recursos digitais utilizados possuem um sistema de feedback imediato, que permitiu que os alunos refletissem sobre seus erros e acertos a medida que respondessem as perguntas. Esta dinâmica é comumente encontrados em games, estimulando os jogadores a desenvolverem competências e habilidades para aprender/evoluir. No contexto da educação, esta estratégia pode ser associada aos princípios da aprendizagem, permitindo que os alunos sejam recompensados (reforço positivo) ou não (reforço negativo) durante sua experiência nos jogos lúdicos [Carvalho et al. 2016].

Na utilização do aplicativo Kahoot! verificou-se que houve uma intensa competição entre os alunos, principalmente quando eram disponibilizados os relatórios do "Ranking". Esta dinâmica estimulava os alunos a se manterem participativos na busca pela vitória. De maneira semelhante, Maranhão \& Reis (2019) apontaram em seu estudo que os alunos tiveram um aumento de interesse, concentração e desempenho à medida que suas pontuações aumentavam.

Ademais, outros autores destacam que a utilização desses recursos digitais proporciona um ensino colaborativo, no qual, os professores, monitores e alunos podem interagir e trocar conhecimentos prévios e adquiridos durante o jogo. Esses jogos educativos digitais, além de inovarem no conhecimento, visam a descoberta, a investigação e proporcionam inovação no espaço interativo de aprendizagem [Mattar 2010].

No que se refere aos recursos não digitais utilizados como metodologias ativas, têmse o "Quebra-cabeça Histológico"e o "Caça ao Microscópio". Durante a construção do quebra-cabeça histológico, os alunos foram estimulados a discutirem entre si a fim de identificarem as peças corretas para montagem do órgão estudado. Este jogo demandou que os alunos discutissem entre si a fim de decidir qual qual peça melhor se encaixava com a descrição das estruturas e as características visíveis.

Já o "Caça ao microscópio" levou os alunos a percorrerem o laboratório na procura por "seu microscópio". A corrida pela identificação estimulou os alunos a visualizarem estruturas e sistemas histológicos que não tinham percebido anteriormente, e através desse jogo, puderam se atentar aos detalhes que os levaram à identificação. Esse jogo também acarretou no estímulo ao trabalho em equipe, uma vez que os estudantes foram divididos em duplas para a identificação das lâminas. Atrelado a isso, foi observado que, além de criar um ambiente lúdico, interativo e descontraído, esse recurso também proporcionou a discussão do assunto entre as duplas, maior engajamento com os monitores e familiaridade com os conteúdos apresentados [Gazotti-Vallim; Gomes; Fischer 2017].

Dessa maneira, entende-se que a incorporação da gamificação através desses recursos não digitais também promoveu um ambiente interativo na sala de aula, expondo os alunos a dinâmicas que os desafiavam a conquistar um objetivo comum através da cooperação, necessários para completar o "Quebra-cabeça Histológico" e concluir a "Caça ao microscópio". Desse modo, pôde-se estimular os alunos a desenvolverem habilidades 
interpessoal e de trabalho em equipe. A incorporação da aprendizagem colaborativa através de métodos baseados em jogos na sala de aula permite que os alunos aprendam de maneira relaxada e prazerosa, melhorando sua consciência de equipe e habilidade de colaborar [Zhong 2019].

\section{Considerações finais}

Diante do exposto, observa-se que os recursos tecnológicos e digitais podem ser incorporados nas práticas de ensino da morfologia transformando a sala de aula em um ambiente mais ativo e incentivando os alunos se tornarem mais responsáveis por sua aprendizagem. Além disso, ressalta-se que os jogos e as dinâmicas que possuem finalidades pedagógicas são ferramentas potencialmente poderosas no ensino da histologia ao tornar o processo de ensinoaprendizagem mais divertido e prazeroso.

A experiência de selecionar, construir e planejar os encontros na sala de aula foram capazes de proporcionar aos monitores o desenvolvimento de habilidades inerentes à prática docente. A busca pela inovação e inserção de tecnologias e recursos digitais viabilizam uma constante renovação de estratégias de ensino da histologia humana, essenciais para os docentes nos dias de hoje.

\section{Referências}

Alonso, C. Introducción al uso de imágenes digitales em formato web em el aprendizaje de la histologia humana. Educ Med. 2018.

Attard, C., \& Holmes, K. (2020). "It gives you that sense of hope": An exploration of technology use to mediate student engagement with mathematics. Heliyon, 6(1), e02945.

Barrows, H. S. \& Tamblyn. R. M. (1980). Problem-based learning: An approach to medical education. New York: Springer.

Bunchball, I. (2010). Gamification 101: An introduction to the use of game dynamics to influence behavior. White paper, 9.

Burity, C. H. F.; Cardozo, S. V. (2014) Atlas digital de morfologia comparada: uma ferramenta complementar ao ensino de histologia e histopatologia. Revista UNIABEU.

Carvalho, A. A., Cruz, S., Barros, C., Moura, A., Araújo, I., \& Zagalo, N. (2016). Aspetos a considerar na criação de jogos educativos. Carvalho, AAA; Cruz, S.; Marques, CG; Moura, A, 510-518.

Cavadas, C. et al. (2017) Quizzes as an active learning strategy: a study with students of pharmaceutical sciences. In: 2017 12th Iberian Conference on Information Systems and Technologies (CISTI). IEE, p. 1-6.

Cavanagh, A. J. et al. (2018). Trust, growth mindset, and student commitment to active learning in a college science course. CBE-Life Sciences Education, v. 17, n. 1, p. ar10.

De Moraes, J. V., \& Castellar, S. M. V. (2018). Metodologias ativas para o ensino de Geografia: um estudo centrado em jogos. Revista Electrónica de Enseñanza de las Ciencias, 17(2), 422-436. 
De Ovando Solís, A.; Rodriguez, A.; Hullin, C. (2018) Digital Game-Based Learning: A Didactic Experience in the Pre-Degree Nursing Career. Studies in health technology and informatics, v. 250, p. 88-88.

Diesel, A.; Baldez, A. L. S.; Martins, S. N. (2017). Os princípios das metodologias ativas de ensino: uma abordagem teórica. Revista Thema, v. 14, n. 1, p. 268-288.

Fidalgo-Blanco, Á.; Sein-Echaluce, M. L.; García-Peñalvo, F. J. (2019). Enhancing the main characteristics of active methodologies: A case with Micro Flip Teaching and Teamwork.

Gazotti-Vallim, M. A., Gomes, S. T., \& Fischer, C. R. (2017). Vivenciando inglês com Kahoot. The ESPecialist, 38(1).

Maranhão, K. M.; Reis, A. C. S. (2019). Recursos de gamificação e materiais manipulativos como proposta de metodologia ativa para motivação e aprendizagem no curso de graduação em odontologia. Revista Brasileira de Educação e Saúde, v. 9, n. 3, p. 1-7.

Mattar, J. (2010). Games em educação: como os nativos digitais aprendem.

Ribeiro, J.; Gil, H. (2016). A utilização dos recursos educativos digitais-RED: na prática de ensino supervisionada no $1{ }^{\circ} \mathrm{CEB}$. In: $11^{\mathrm{a}}$ Conferencia Ibérica de Sistemas y Tecnologias de Información. AISTI (Associação Ibérica de sistemas e tecnologias de Informação), p. 85-89.

Ribeiro, L. C. V. (2018). Testando novas metodologias de aprendizagem para o ensino de embriologia humana: relato de experiência e percepção dos discentes. Revista Docência do Ensino Superior, v. 8, n. 1, p. 151-165.

Risnes, S., Khan, Q., Hadler-Olsen, E., \& Sehic, A. (2019). Tooth identification puzzle: A method of teaching and learning tooth morphology. European Journal of Dental Education, 23(1), 62-67.

Silva, J. B. D., Sales, G. L., \& Castro, J. B. D. (2019). Gamificação como estratégia de aprendizagem ativa no ensino de Física. Revista Brasileira de Ensino de Física, 41(4).

Zhong, Q. (2019). Design of Game-Based Collaborative Learning Model. Open Journal of Social Sciences, 7(07), 488. 